\title{
Low-Level Laser Irradiation Promotes Proliferation and Differentiation on Apical Papilla Stem Cells
}

\author{
David Gutiérrez $^{\circledR}$, Mahmoud Rouabhia $^{2^{\circledR}}$, Javiera Ortiz $^{3}{ }^{\circledR}$, Diego Gaviria $^{4}$, Camilo Alfonso $^{(\oplus}$, Ana \\ Muñoz $^{6,7}$, Carolina Inostroza ${ }^{8^{*}}$ \\ ${ }^{1}$ Faculty of dentistry, Buccal Innovation research group, Antonio Nariño University, Bogotá, Colombia \\ ${ }^{2}$ Faculty of Dentistry, Laval University, Quebec, Canada \\ ${ }^{3}$ Centro de Investigación e Innovación Biomédica (CIIB), Faculty of Medicine, Universidad de los Andes, Santiago, \\ Chile \\ ${ }^{4}$ Artek Laser Dentistry, Bogotá, Colombia \\ ${ }^{5}$ Faculty of Dentistry, Research Group of Oral Health, Antonio Nariño University, Bogotá, Colombia \\ ${ }^{6}$ Faculty of Science, Cellular and Functional Biology and Biomolecule Engineering Research Group, Antonio \\ Nariño University, Bogotá, Colombia \\ ${ }^{7}$ Hemolife National Blood Bank Foundation \\ ${ }^{8}$ Center for Research and Biomedical Innovation (CIIB), Faculty of Medicine, Universidad de los Andes, Santiago, \\ Chile
}

\section{*Correspondence to} Carolina Inostroza Silva, Centro de Investigación e Innovación Biomédica (CIIB), Facultad de Medicina, Universidad de los Andes, Santiago PC 7620001 Chile Tel: +56984691314 Email: cminostroza@uandes.cl

Received: May 5, 2021 Accepted: September 9, 2021 Published online December 1 , 2021

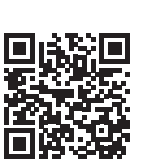

\begin{abstract}
Introduction: Low-level laser therapy (LLLT) has been reported to improve cell proliferation and differentiation. The stem cells derived from dental apical papilla (SCAPs) are a promising therapy because they are easily obtained from immature human teeth. The effect of LLLT over SCAPs is still unknown. This study aimed to evaluate the proliferation and osteogenic potential of the SCAPs stimulated with LLLT.

Methods: SCAPs were isolated from the third molars of a healthy donor and characterized according to the minimum established criteria. SCAPs were cultured for 24 hours before being exposed to LLLT. Cells were exposed to different doses, energy, and wavelengths for selecting the irradiation parameters. SCAPs proliferation was evaluated with the MTT assay at 24 hours and 7-day post-laser exposure. VEGF and TGF 32 expression were assessed with a specific enzyme-linked immunosorbent assay (ELISA). The osteogenic differentiation potential was analyzed with alizarin red staining, and the nodule quantification was performed by the relative optical density (ROD) analysis using ImageJ software.

Results: The cells isolated from the apical papilla showed phenotype and stem cell properties. SCAPs irradiated with one dose at $6 \mathrm{~J} / \mathrm{m}^{2}$ and $650 \mathrm{~nm}$ exhibited significantly higher proliferation $(P>0.05)$ than the controls nonirradiated. LLLT stimulated SCAPs' expression of factors VEGF and TGF 32 . Also, SCAPs irradiated showed higher osteogenic activity $(P<0.05)$.

Conclusion: LLLT promotes proliferation, osteogenic differentiation, and VEGF and TGF 32 expression on SCAPs. LLLT is a practical approach for the preconditioning of SCAPs in vitro for future regenerative therapies. More studies are needed to determine the underlying molecular processes that determine the mechanism of the LLLT.
\end{abstract}

Keywords: Low-level laser therapy; Apical papilla stem cells; Cell differentiation; Cell proliferation.

\section{Introduction}

The apical papilla tissue is only present during root development before the tooth erupts. There is a cellrich zone known as stem cells derived from dental apical papilla (SCAPs) ${ }^{1,2}$ SCAPs are easily obtained from soft tissues attached to the apices of immature permanent third molars or first premolars teeth, which require extraction for orthodontic indication. ${ }^{3,4}$ SCAPs can differentiate into various cell types and possess low immunogenicity, which could be considered an attractive alternative cell source for stem cell-based therapy. ${ }^{5}$

SCAPs express a panel of angiogenic factors, such as vascular endothelial growth factor (VEGF) and basic fibroblast growth factor $(\mathrm{BFGF})^{6}$; these growth factors contribute to the revascularization and the regeneration of the dentino-pulpal organ and promoting the tooth maturation. ${ }^{7}$ Stem cells, therefore, are considered promising candidates for stem cell-based therapies..$^{8-11}$

Please cite this article as follows: Gutiérrez D, Rouabhia M, Ortiz J, Gaviria D, Alfonso C, Muñoz A, et al. Low-level laser irradiation promotes proliferation and differentiation on apical papilla stem cells. J Lasers Med Sci. 2021;12:e75. doi:10.34172/jlms.2021.75. 
Low-intensity laser radiation is a non-invasive cell inductor that induces athermic, nondestructive photobiological processes. $^{12}$ The photobiomodulation therapy, specifically low-level laser therapy (LLLT), has advantages such as pain relief, vasodilation, ${ }^{13}$ tissue healing, ${ }^{14}$ promoting cell proliferation, ${ }^{15,16}$ mineralization, ${ }^{17}$ and osteoinduction. ${ }^{18}$ Many parameters can influence the response of cells to lasers. Besides the energy density, power density, and irradiation mode (continuous or pulsed), the most important single parameter is the wavelength. The application of LLLT in a visible spectrum of 600 to $700 \mathrm{~nm}$ at an energy density of 0.5 to $4.0 \mathrm{~J} / \mathrm{cm}^{2}$ increases the proliferation rate of various cell lines. ${ }^{19,20}$

Since LLLT has scientifically been proven to act as a beneficial therapeutic modality for numerous diseases and diseased conditions, it was applied to enhance the mesenchymal stem cells (MSCs) proliferation and differentiation. ${ }^{21}$ Abrahamse's group published some literature for LLLT application to stem cells, demonstrating an increased cell proliferation and viability that may significantly contribute to the addition of LLLT to the many biomedical disciplines that further augment the successes of regenerative medicine. ${ }^{22}$

There is minimal evidence of the LLLT effect on the SCAPs' functional properties. Our objective was to evaluate the impact of the LLLT on the SCAPs proliferation and osteogenic differentiation. Also, our interest was focused on the expression of VEGF and TGF $\beta 2$ factors. The aspects evaluated in this study will allow the design of a cell preconditioning protocol before transplantation based on LLLT and SCAPs for dental tissue engineering/ regeneration. LLLT could promote SCAPs proliferation and differentiation, which may contribute to tissue regeneration and wound healing in the oral cavity.

\section{Materials and Methods \\ Isolation and Characterization of SCAPS}

Apical papilla tissues were obtained from four third molars of healthy volunteers (16-19 years old), who signed informed consent. Anonymity is guaranteed according to the Helsinki Declaration. The extraction procedure was at the dental clinic service of the Universidad Antonio Nariño. Apical papilla tissue was removed and seeded in 4 culture flasks (Falcon; BD Lab-ware, Franklin Lakes, NJ). The culture medium was Dulbecco's Modified Eagle Medium (DMEM, Lonza ${ }^{\circledR}$ High glucose, and glutamine) supplemented with $5 \%$ fetal bovine serum (FBS, Gibco ${ }^{\circledR}$ ), $0.1 \mu \mathrm{M}$ L-glutamine (Invitrogen) and $1 \%$ penicillin/streptomycin (10000IU Invitrogen) at $37^{\circ} \mathrm{C}$ in a humidified atmosphere containing $5 \% \mathrm{CO}_{2}$ $\left(\right.$ Sanyo $\left.{ }^{\mathrm{ms}}\right)$. SCAPs in passages $2-5$ were fully characterized. Phenotyping was assayed by flow cytometry (BD Accuri ${ }^{\text {Tw }}$ C6), using the following antibodies: CD34 (LifeSpan Bioscience \#LSC204500), CD45 (eBioscience \#11-
9459-42), CD90 (eBioscience \#12-0909-42) and CD105 (Sigma-Aldrich \#SAB4700259-100), according to the manufacturer's recommendations. The multilineage differentiation assay was performed according to the protocols previously described., ${ }^{3,23}$ Briefly, after ten days in the respective culture medium, the cells were stained with Alizarin Red and Alcian blue (TMS-008 and TMS010, Sigma-Aldrich Germany) for osteogenic and chondrogenic differentiation respectively. Images were captured in an optical microscope (Leica DMiL, Wetzlar, Germany) at 10x.

\section{LLLT Irradiation Procedures}

LLLT experiments were performed with the therapeutic laser lamp (DMC Therapy-XT ${ }^{\circledR}$, São Carlos, SP, Brazil). The specifications are described below (Table 1). Initially, we used a digital photometer (Industrial Fiber Optics ${ }^{\circledR}$, Tempe, AZ, USA) (sensitivity 450-1050 nm) to evaluate the received energy in different diameters of culture well, medium, spot distance, and collateral irradiation conditions. The LLLT device was fixed to base support to guarantee the irradiation angle of $90^{\circ}$ in all experiments.

$1.5 \times 10^{4}$ SCAPs $/ \mathrm{mL}$ at 4 or 5 passages were seeded in DMEM in a 12 -well cell culture plates (Falcon; BD Labware, Franklin Lakes, NJ) at $37^{\circ} \mathrm{C}$ with $5 \% \mathrm{CO}_{2}$. After 24 hours, SCAPs were irradiated with energy levels of 4,6 , or $8 \mathrm{~J} / \mathrm{cm}^{2}$ and then with different doses, one dose of $6 \mathrm{~J} / \mathrm{cm}^{2}$ and two doses of $3 \mathrm{~J} / \mathrm{cm}^{2}$ ( 6 hours apart from each other); finally, different wavelengths were evaluated: $\operatorname{red}(\mathrm{R}) 650$ $\pm 10 \mathrm{~nm}$, infrared (IR) $808 \pm 10 \mathrm{~nm}$, and R+IR. SCAPs nonirradiated were used as negative controls.

\section{Effect of LLLT on SCAPs Proliferation}

SCAPs proliferation analysis was performed with the MTT assay $\left(\right.$ Roche $^{\circledR}$ ) according to the manufacturer's recommendations. $1.0 \times 10^{4} \mathrm{SCAPs} / \mathrm{mL}$ were seeded in 12 -well plates with $1 \mathrm{~mL}$ of DMEM. After 24 hours of culture, the cells were irradiated $\left(650 \mathrm{~nm}, 6 \mathrm{~J} / \mathrm{cm}^{2}\right.$ for a single dose), or they were not irradiated (control). DMEM

Table 1. Summary of the Laser Parameters Used to Irradiate the Stem Cells From Apical Papilla

\begin{tabular}{lcc}
\hline Parameter & Setting & Unit \\
\hline Type of laser & Diode & \\
Wavelength & 650,880 & $\mathrm{~nm}$ \\
Spot size (diameter) & 0,75 & $\mathrm{~cm}$ \\
Energy density & $1-10$ & $\mathrm{~J} / \mathrm{cm}^{2}$ \\
Emission mode & Continue & \\
Pulse frequency & 60 & $\mathrm{~Hz}$ \\
Peak power output & 100 & $\mathrm{~W}$ \\
The shape of the laser beam & Circular & \\
Doses of exposition & 1,2 & $\begin{array}{c}\text { Times per } \\
\text { experiment }\end{array}$ \\
\hline
\end{tabular}


was replaced every three days, and MTT analysis was performed at 7 and 14 days' post-irradiation, following the manufacturer's recommendations.

\section{Effect of LLLT on SCAPs Differentiation to Osteoblasts} $1.5 \times 10^{4} \mathrm{SCAPs} / \mathrm{mL}$ were seeded in $1 \mathrm{~mL}$ of the culture medium into 12 -well plates in two aleatory groups (control and LLLT) and incubated for 24 hours at $37^{\circ} \mathrm{C}$ in a humid atmosphere with $5 \% \mathrm{CO}_{2}$ for adherence. After incubation, the cells were exposed to a fresh osteogenic medium (0.1 $\mu \mathrm{M}$ dexamethasone, $10 \mathrm{mM} \beta$ glycerophosphate, and $50 \mu \mathrm{M}$ ascorbic acid). ${ }^{23}$ SCAPs were irradiated with LLLT ( $650 \mathrm{~nm}, 6 \mathrm{~J} / \mathrm{cm}^{2}$, and one dose). After exposure to LLLT, the cells were cultured for 15 days, then subjected to Alizarin Red staining assay. Relative optical density (ROD) was quantified and calculated by using public domain software (NIH, Bethesda, MA, USA). Five images per culture condition were captured at $10 \mathrm{x}$ in an optical microscope (Leica DMiL, Wetzlar, Germany) to quantify mineralization $\left(>0.04 \mathrm{~mm}^{2}\right)$ by a percentage of the stained area.

\section{Effect of LLLT on the Secretion of Growth Factors by SCAPs}

An enzyme-linked immunosorbent assay (ELISA) was performed in the supernatants at 24 hours and on days 7 and 14 to determine the secretion levels of VEGF (Invitrogen ${ }^{\circledR}$, Thermo Fisher Scientific, KHGO111, sensitivity $10 \mathrm{pg} / \mathrm{mL}$, range $8.3-6000 \mathrm{pg} / \mathrm{mL}$ ) and TGF $\beta 2$ (Quantikine $^{\circledR}$ ELISA R\&D Systems, Minneapolis, MN,
USA, DB100B, sensitivity $15.4 \mathrm{pg} / \mathrm{mL}$, range $10-200 \mathrm{pg} /$ $\mathrm{mL})$. According to the manufacturer's recommendations, the plates were read with a spectrophotometer (Thermo Scientific $^{\mathrm{TM}}$ Multiskan $^{\mathrm{TM}}$ GO- 51119200).

\section{Statistical Analysis}

The proliferation and osteogenic differentiation data were expressed as means with Standard Deviation $( \pm)$ of at least three independent experiments. A two-way ANOVA test with Tukey's post hoc test was used for intergroup comparisons. A paired student $t$ test was used for intergroup comparison (SPSS, Inc, Chicago, Ill, USA). Statistical significance was defined as $P<0.05$.

\section{Results}

\section{Stem Cell Phenotype}

In this study, the cells were isolated from the apical papilla tissues of four undeveloped third molars roots (Figure 1A). The teeth demonstrated different root developments (Nolla stage 8-9) (Figure 1B). The cells isolated exhibited features of stem cells with the adherent and elongated phenotype and growth as colonies (Figure 1C). They showed multilineage differentiation potential (Figure 1D, 1E). The stem cell phenotype was confirmed by the positive expression of CD90 and CD105, and negative expression of CD34 and CD45 (Figure 1F).

\section{LLLT Promotes SCAPs Proliferation}

Our irradiation parameter results showed that the energy received in the well depends on the size of the well plate,

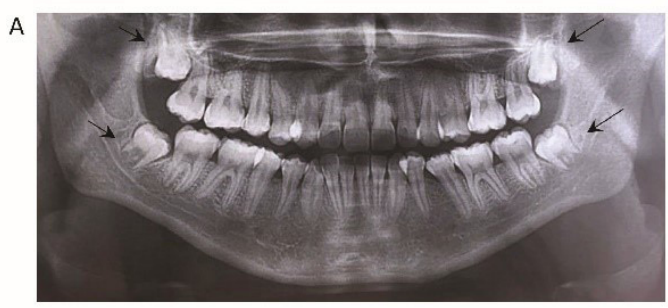

B
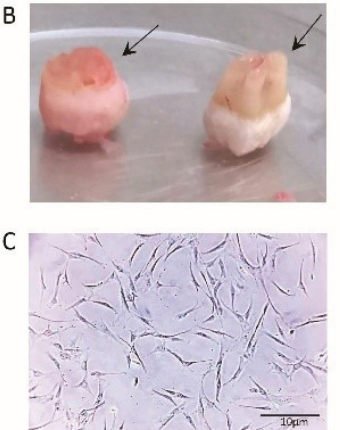
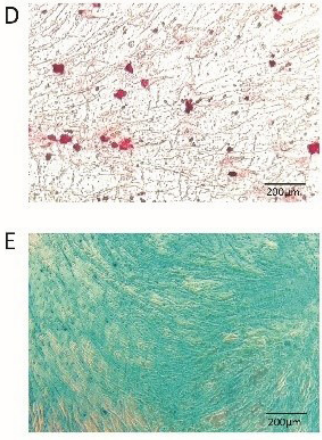

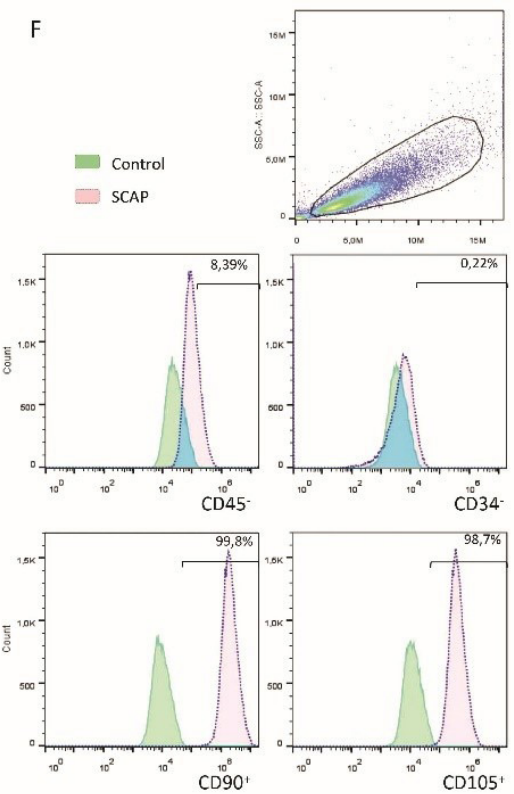

Figure 1. (A) Dental Panoramic X-ray. Third molars stood out with different formation stages. (B) Third molars extracted. The arrow showed different sizes of apical papilla tissues. (C) Cell morphology. Cells derived from apical papilla showed typical fibroblast-like morphology and plastic adherence; magnification bars indicate $10 \mu \mathrm{m}$. (D) Multilineage differentiation potential. Mineralized areas, according to calcium deposits, were detected for osteogenic lineage with Alizarin red staining. (E) Chondrogenic differentiation showed the phenotype of mucopolysaccharide matrix with Alcian blue staining. (F) Immunophenotypic Profile. Cells expressed the surface markers CD45-, CD34-, CD90+, and CD105+; green histograms represented the control group, and red histograms were the patterns of the experimental condition. 
the distance of the spot, and the volume of the media (Figure 2). The changes in the laser parameters affect the response of the SCAPs. SCAPs' proliferation rate increased according to energy $\left(4,6\right.$, and $\left.8 \mathrm{~J} / \mathrm{cm}^{2}\right)$, but no significant differences were observed between 6 and $8 \mathrm{~J} / \mathrm{cm}^{2}(P=0.294)$ (Figure $\left.3 \mathrm{~A}\right)$. Regarding the dose, the single dose $\left(6 \mathrm{~J} / \mathrm{cm}^{2}\right)$ did not show significant differences in comparison with the two-dose of $3 \mathrm{~J} / \mathrm{cm}^{2}(P=0.878)$
(Figure 3B). The irradiation at a wavelength of $650 \mathrm{~nm}$ (Red) induced a significant increase $(P=0.048)$ in the proliferative response in comparison with the infrared $(808 \mathrm{~nm})$ (Figure 3C). Also, it confirmed a significant increase $(P=0.0002)$ in the proliferation rate of the SCAPs irradiated with $6 \mathrm{~J} / \mathrm{cm}^{2}$, single-dose, and $650 \mathrm{~nm}$ in comparison with the control (Figure 3D).
A

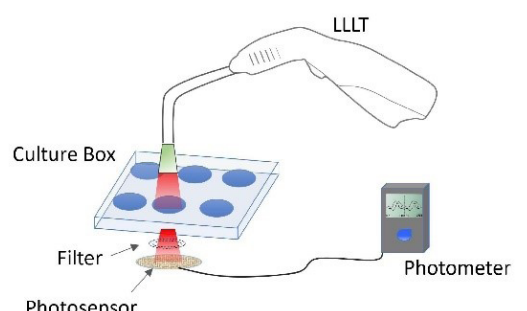

B

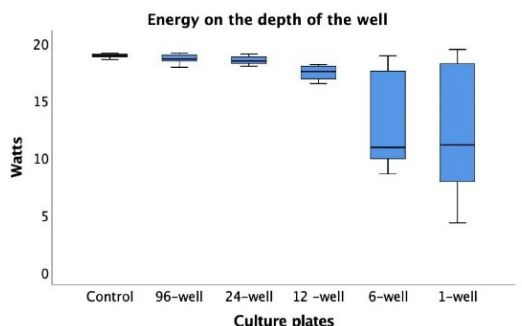

$\mathrm{E}$

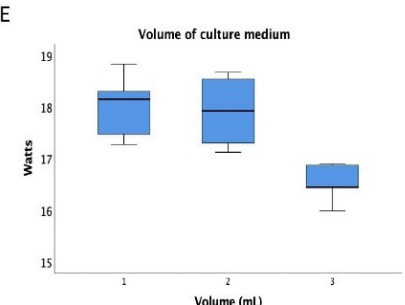

Figure 2. (A) Graphic representation of the energy irradiation assessment. (B) The energy received in the depth of the empty culture-box with unique LLLT exposition shows a significant decrease in mean energy in both 6-well and 1-well boxes. (C) The energy received in the adjacent well of 96-well and 24-well boxes was significantly higher in comparison with 12-well and 6-well boxes (D) The assessment of the medium DMEM, PBS, and DMEM-Supplemented irradiation shows no significant differences between the energy received in the depth of the well, (E) The assay with different medium volumes shows no significant differences between 1 and $2 \mathrm{ml}$, but with $3 \mathrm{ml}$ the energy received decreases.

A

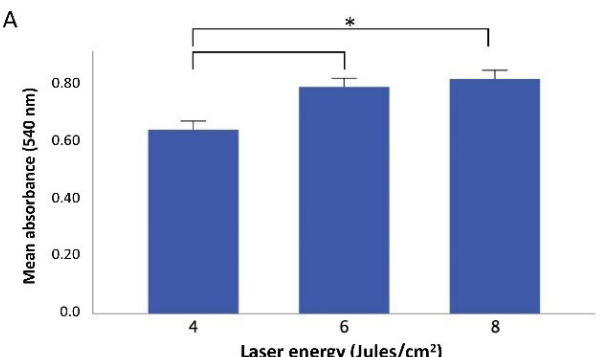

$\mathrm{C}$

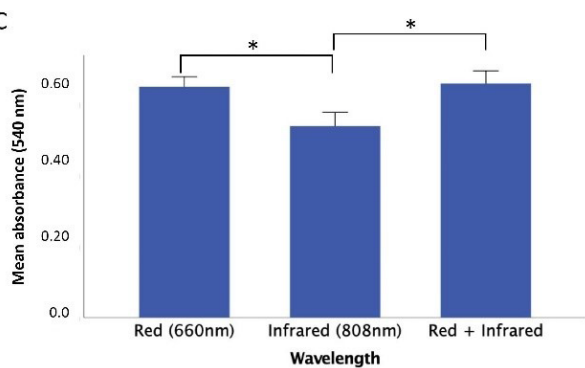

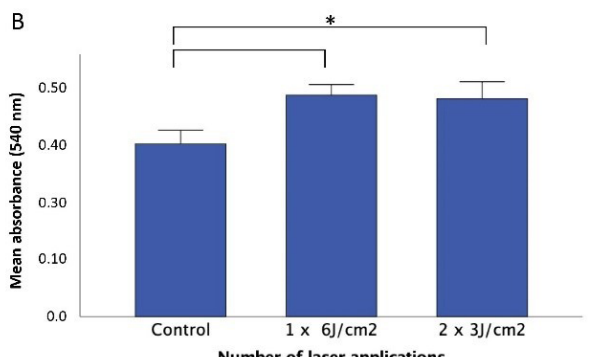

D

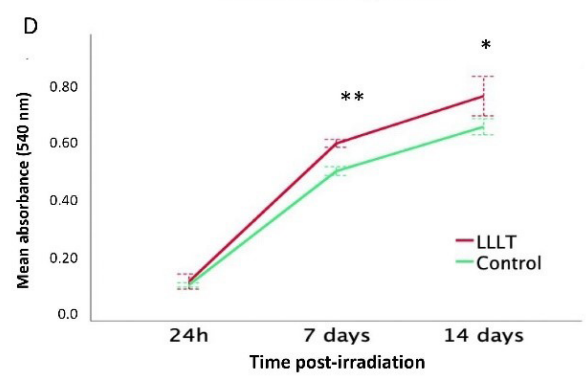

Figure 3. SCAPs Proliferation Curves in Response to LLLT With Different Laser Parameters. (A) at 4, 6, and $8 \mathrm{~J} / \mathrm{cm}^{2}$. (B) SCAPs proliferation rate with different doses of LLLT. Control group without irradiation, single irradiation $6 \mathrm{~J} / \mathrm{cm}^{2}$, two irradiations of $3 \mathrm{~J} / \mathrm{cm}^{2}$. (C) The response of SCAP to LLLT exposition with different wavelengths $(650 \mathrm{~nm}, 808 \mathrm{~nm}$, and a combination of both). (D) SCAPs proliferation curve at $6 \mathrm{~J} /$ $\mathrm{cm}^{2} 650 \mathrm{~nm}$, single exposition and dose on day 14. The Control group not irradiated showed in the blue line versus the experimental group in the red line. Asterisk indicates different levels of statistical significance $\left({ }^{* *} P<0.01 ;{ }^{*} P<0.05\right)$. 


\section{Calcium Deposition Analysis}

The SCAPs stimulated with LLLT showed higher calcium deposition, evidenced with alizarin red positive stain compared to the control (Figure 4A). Quantitative analyses showed that the percentage of nodules areas on day 14 was significantly higher $(P=0.001)$ in the LLLT group compared to the control (Figure $4 \mathrm{~B}$ ).

\section{Expression of TGF $\beta 2$ and VEGF}

The ELISA analysis shows that at 24 hours and on day 7 , the mean for both VEGF and TGF 32 was higher in the LLLT groups. The secretion of VEGF on day 7 was slightly higher than the control, but on day 14 , the increase was more significant (Figure 5A). On the contrary, the TGF $\beta 2$ expression was more critical on day 7 and decreased on day 14 (Figure 5B).

\section{Discussion}

The LLLT promotes the proliferation and differentiation of stem cells from different sources, such as bone marrow, adipose tissue, and umbilical cord, ${ }^{21}$ but these cells have limitations for obtaining. The SCAPs are dental stem cells with high potential in regenerative medicine and are easily obtained. One option to increase the potential of the stem cells is the application of LLLT, which has not been probed in SCAPs. This study aimed to evaluate the effect of the LLLT on the proliferation and osteogenic potential of SCAPs.

In our study, the teeth presented different root developments (Nolla stage 8-9), with incomplete root formation contributing to the collection of enough apical papilla tissue from all samples. The collected tissues contribute to isolating and expanding SCAPs as previously described. ${ }^{3}$ The cells isolated from apical papilla shared the phenotypic features described by Dominici et $\mathrm{al}^{24}$ and expressed surface markers as in previous studies. 9,25 Therefore, our results confirm that human apical papilla tissue is easily accessible and has proven to be an abundant source of stem cells.

Before the irradiation test, different conditions were compared to minimize the possible loss of energy. ${ }^{26}$ Accordingly, we established that the power received at a depth of the well was affected by the size (diameter) of the well plate, the distance of the point, and the volume of the medium. ${ }^{5}$ Multiple laser protocols have been described, with variations in wavelength, power density, and radiation time. ${ }^{27}$ This variety in laser protocols determines that it is necessary to standardize the parameters and
A

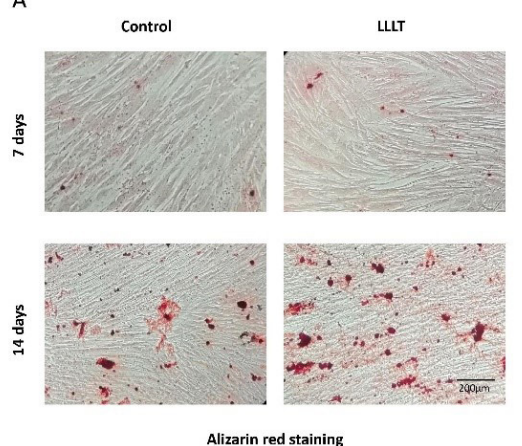

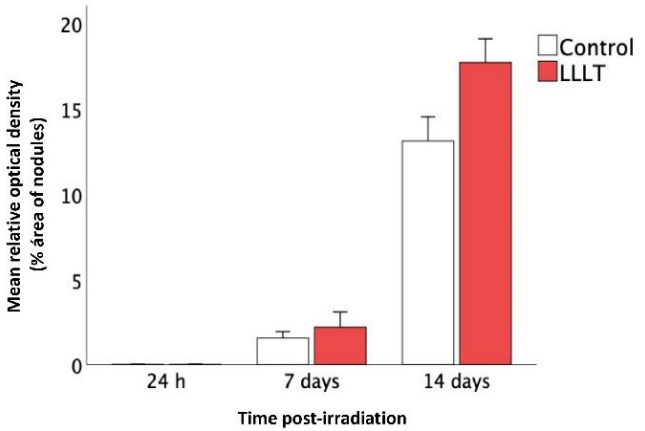

Figure 4. Osteogenic Differentiation of SCAPs. (A) Photographs of wells of SCAPs with the osteogenic induction medium irradiated or not on days 7 and 14. (B) Percentage of optical density (\%OD) of nodule areas evaluated at different times post-irradiation (24 h, days 7 and 14). Asterisk indicated statistically significant differences in mineralized tissue deposition of SCAPs irradiated compared to nonirradiated groups on day $14(P<0.05)$.

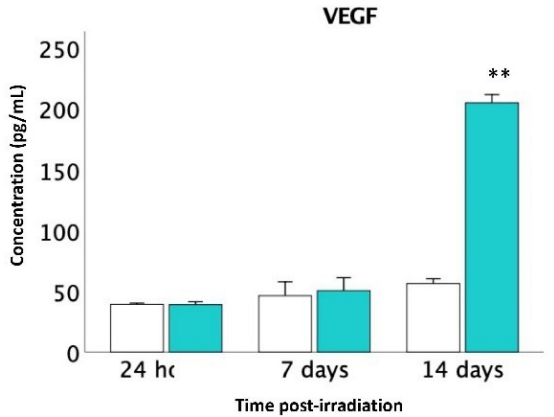

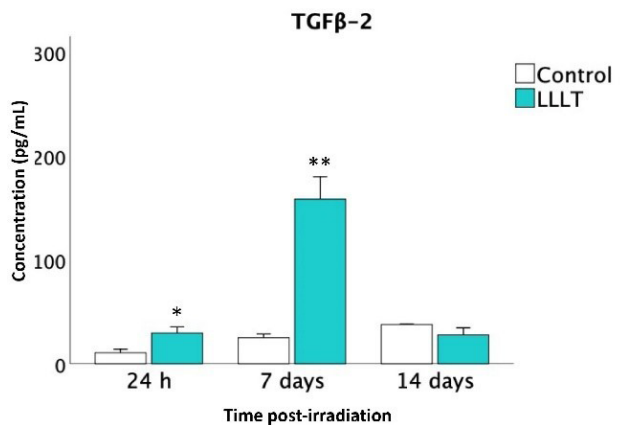

Figure 5. Levels of Expression of Growth Factors in Supernatants Determined by ELISA on Days 7 and 14 Post-irradiation. (A) VEGF. (B) TGF 32 . Asterisk indicates different levels of statistical significance $(* * P<0.01 ; * P<0.05)$. 
measure the energy to determine the optimal conditions before applying the therapy.

The LLLT parameters used in our study $\left(6 \mathrm{~J} / \mathrm{cm}^{2}\right.$, singledose, and $650 \mathrm{~nm}$ ) differ from other studies in the cell target, laser equipment, culture conditions (well plates, spot diameter), and cell concentration. ${ }^{28}$ Therefore, we considered it a key to the establishment of the irradiation parameters and the cell type to determine the best aspects for stimulation. Our study showed the LLLT positive effects on SCAPs proliferation. Similarly, Huertas et $\mathrm{al}^{29}$ reported the expansion of MG-63 with low-power diode laser irradiation at $940 \mathrm{~nm}$, and they found different proliferation rates with energies of $1-5 \mathrm{~J} / \mathrm{cm}^{2}$. We want to highlight that it is the first study demonstrating a similar effect of LLLT with SCAPs.

The high osteogenic potential of SCAPs was reported in comparison with DPSCs and BMSCs. ${ }^{1,5}$ In the present study, we assessed the osteogenic potential of SCAPs following exposure to LLLT. We found that alizarin red stain showed higher deposition of calcium nodules with significant differences in comparison with the control group $(P<0.05)$. The LLLT improvement the osteogenesis over SCAPs in vitro because laser irradiation could modulate SCAPs osteogenic differentiation significantly. Studies in different stem cells have also proven LLLT's capability of enhancing osteogenic differentiation. ${ }^{30-32}$ Although one study reported osteogenic differentiation of SCAPs with blue LED irradiation, ${ }^{33}$ the literature showed the detrimental effects of blue LED on some types of cells. ${ }^{34}$ Even though the mechanism of the laser on SCAPs osteogenic differentiation needs further study, we conclude that different light irradiation parameters can improve osteogenic differentiation in SCAPs.

Regarding growth factor levels, our data showed that LLLT could positively modulate them. The influence of laser radiation at $635 \mathrm{~nm}, 1.875 \mathrm{~mW} / \mathrm{cm}^{2}$ demonstrated a significant increase in endothelial cell proliferation and a corresponding decrease in VEGF concentration, suggesting the role of VEGF in this process. The irradiation at $830 \mathrm{~nm}, 3.75 \mathrm{~mW} / \mathrm{cm}^{2}$ was associated with a reduction in TGF- $\beta$ secretion. ${ }^{35}$

The role of the TGF has shown to be effective on precursor cells of the osteoblast lineage and the extracellular matrix synthesis, thereby enhancing the quality of bone formation. Also, VEGF is an essential mediator of vasculogenesis, actively involved in wound healing. The mechanism involved in the laser activation of the VEGF gene is mediated by mRNA levels of interleukin-1 alpha and interleukin-8 from cultured human keratinocytes. ${ }^{14}$

To obtain better tissue regeneration, it is necessary to promote cell proliferation and differentiation. The LLLT influences the release of chemical mediators, diminishing the local inflammation and consequently promoting healing and tissue regeneration. ${ }^{36}$ We hypothesized that the action of the LLLT on SCAPs could begin with the photo-induction of cytochrome c-oxidase, which acts in two ways: generating necessary ions for the ATP synthesis ${ }^{37}$ and activating the release of molecules that become second messengers. With the ATP increase, cells increase energy availability, stimulate transcription, and proliferate more rapidly. The second messengers act in other pathways interacting with intermediate proteins associated with osteogenic differentiation.

Stem cell-based therapy is an emerging field as a promising treatment of multiple diseases. SCAPs have multilineage differentiation potential and possess immune properties, contributing to the regeneration and repair of tissues as an attractive alternative cell source. ${ }^{9}$ Our results provide a new foundation that supports the future application of SCAPs with the LLLT. Still, future studies should focus on the LLLT-stem cell activation mechanisms of immunomodulation, chemotaxis, and adhesion, among others.

\section{Conclusion}

LLLT promotes the proliferation and osteogenic differentiation of stem cells from apical papilla at $6 \mathrm{~J} / \mathrm{cm}^{2}$, single-dose, and $650 \mathrm{~nm}$. This suggests the potential use of LLLT to promote tissue regeneration.

\section{Ethical Considerations}

The ethical committee approved all ethical aspects and protocols of the Universidad Antonio Nariño (No. 12042017).

\section{Conflict of Interests}

The authors declare that this research was conducted in the absence of any commercial or financial relationships that could be as a potential conflict of interest.

\section{Funding}

This work was supported by funds from the Vice-rectory of Science Technology and Research (VCTI) of the Universidad Antonio Nariño (Grants 2018209). David Gutierrez was supported by the Program of Formation of High Level (PFAN) of the Universidad Antonio Nariño, and the Sistema Nacional de Regalías (SGR) de Colombia and by the project INNOVACCION Cauca.

\section{Acknowledgments}

The authors thank the Dental Clinic of the Universidad de Los Andes and the Centro de Investigación e Innovación Biomédica (CIIB), Facultad de Medicina, Universidad de los Andes, Santiago, Chile.

\section{References}

1. Sonoyama W, Liu Y, Fang D, Yamaza T, Seo B-M, Zhang C et al. Mesenchymal Stem Cell-Mediated Functional Tooth Regeneration in Swine. PLOS ONE. 2006; ;1(1):e79. doi: 10.1371/journal.pone.0000079.

2. Chen F-M, Shi S. Periodontal Tissue Engineering. In: Lanza R, Langer R, Vacanti J (eds). Principles of Tissue Engineering. $4^{\text {th }}$ ed. Academic Press: Boston; 2014:1507- 
1540. doi:10.1016/B978-0-12-398358-9.00072-0

3. Huang GT-J, Sonoyama W, Liu Y, Liu H, Wang S, Shi S. The Hidden Treasure in Apical Papilla: The Potential Role in Pulp/Dentin Regeneration and BioRoot Engineering. J Endod. 2008; 34(6): 645-651. doi: 10.1016/j. joen.2008.03.001

4. Shiehzadeh V, Aghmasheh F, Shiehzadeh F, Joulae M, Kosarieh E, Shiehzadeh F. Healing of large periapical lesions following delivery of dental stem cells with an injectable scaffold: New method and three case reports. Indian J Dent Res. 2014; 25(2): 248-53. doi: 0.4103/0970-9290.135937.

5. Bakopoulou A, Leyhausen G, Volk J, Tsiftsoglou A, Garefis $\mathrm{P}$, Koidis $\mathrm{P}$ et al. Comparative analysis of in vitro osteo/ odontogenic differentiation potential of human dental pulp stem cells (DPSCs) and stem cells from the apical papilla (SCAP). Arch Oral Biol. 2011; 56(7):709-21. doi: 10.1016/j. archoralbio.2010.12.008.

6. Hilkens P, Bronckaers A, Ratajczak J, Gervois P, Wolfs E, Lambrichts I. The Angiogenic Potential of DPSCs and SCAPs in an In Vivo Model of Dental Pulp Regeneration. Stem Cells Int. 2017; 2017: ID2582080. doi: $10.1155 / 2017 / 2582080$

7. Lovelace TW, Henry MA, Hargreaves KM, Diogenes A. Evaluation of the delivery of mesenchymal stem cells into the root canal space of necrotic immature teeth after clinical regenerative endodontic procedure. J Endod. 2011; 37(2):133-8. doi: 10.1016/j.joen.2010.10.009.

8. Arbildo-Vega H, Cruzado-Oliva F, Infantes-Ruiz E. Dental stem cells and their application in dentistry. J Oral Res. 2020; 9(3):220-233. Doi:10.17126/joralres.2020.039.

9. Kang J, Fan W, Deng Q, He H, Huang F. Stem Cells from the Apical Papilla: A Promising Source for Stem Cell-Based Therapy. BioMed Res Int. 2019; 2019: ID6104738. doi: 10.1155/2019/6104738.

10. Raddall G, Mello I, Leung BM. Biomaterials and Scaffold Design Strategies for Regenerative Endodontic Therapy. Front Bioeng Biotechnol. 2019; 7:317. doi: 10.3389/ fbioe.2019.00317.

11. Wang W, Dang M, Zhang Z, Hu J, Eyster TW, Ni L et al. Dentin regeneration by stem cells of apical papilla on injectable nanofibrous microspheres and stimulated by controlled BMP-2 release. Acta Biomater. 2016; 36: 63-72. doi: 10.1016/j.actbio.2016.03.015.

12. Schindl A, Schindl M, Pernerstorfer-Schön H, Schindl L. Low-intensity laser therapy: a review. J Investig Med. 2000; 48: 312-326.

13. Pereira MCMC, de Pinho CB, Medrado ARP, Andrade Z de A, Reis SR de A. Influence of $670 \mathrm{~nm}$ low-level laser therapy on mast cells and vascular response of cutaneous injuries. J Photochem Photobiol B. 2010; 98(3): 188-192. doi: 10.1016/j.jphotobiol.2009.12.005.

14. Basso FG, Oliveira CF, Kurachi C, Hebling J, Costa CA de S. Biostimulatory effect of low-level laser therapy on keratinocytes in vitro. Lasers Med Sci. 2013; 28(2):367-74. doi: 10.1007/s10103-012-1057-8.

15. Kim JE, Woo YJ, Sohn KM, Jeong KH, Kang H. Wnt/ $\beta$ catenin and ERK pathway activation: A possible mechanism of photobiomodulation therapy with light-emitting diodes that regulate the proliferation of human outer root sheath cells. Lasers Surg Med. 2017; 49(10): 940-947.doi: 10.1002/ lsm.22736

16. Pasternak-Mnich K, Ziemba B, Szwed A, Kopacz K, Synder $\mathrm{M}$, Bryszewska $\mathrm{M}$, et al. Effect of Photobiomodulation Therapy on the Increase of Viability and Proliferation of Human Mesenchymal Stem Cells. Lasers Surg Med. 2019;51(9):824-833. doi: 10.1002/lsm.23107.

17. Oliveira F, Matos A, Santesso M, Tokuhara C, Leite A, Lagnato B, et al. Low intensity lasers differently induce primary human osteoblast proliferation and differentiation. J Photochem Photobiol B. 2016; 163:14-21. doi: 10.1016/j. jphotobiol.2016.08.006.

18. Miranda JM, de Arruda JAA, Moreno LMM, Gaião WDC, do Nascimento SVB, Silva EV de S, et al. Photobiomodulation Therapy in the Proliferation and Differentiation of Human Umbilical Cord Mesenchymal Stem Cells: An In Vitro Study. J Lasers Med Sci. 2020; 11(4): 469-474. doi: 10.34172/jlms.2020.73

19. AlGhamdi KM, Kumar A, Moussa NA. Low-level laser therapy: a useful technique for enhancing the proliferation of various cultured cells. Lasers Med Sci. 2012; 27(1): $237-$ 249. doi: 10.1007/s10103-011-0885-2.

20. Zaccara IM, Ginani F, Mota-Filho HG, Henriques ÁCG, Barboza CAG. Effect of low-level laser irradiation on proliferation and viability of human dental pulp stem cells. Lasers Med Sci. 2015; 30(9): 2259-2264. doi: 10.1007/ s10103-015-1803-9

21. Ahrabi B, Rezaei Tavirani M, Khoramgah MS, Noroozian M, Darabi S, Khoshsirat S et al. The Effect of Photobiomodulation Therapy on the Differentiation, Proliferation, and Migration of the Mesenchymal Stem Cell: A Review. J Lasers Med Sci. 2019; 10 (supl.1): S96S103. doi: 10.15171/jlms.2019.S17

22. Kushibiki T, Hirasawa T, Okawa S, Ishihara M. Low Reactive Level Laser Therapy for Mesenchymal Stromal Cells Therapies. Stem Cells Int. 2015; 2015: ID 974864. doi: $10.1155 / 2015 / 974864$

23. Park M-K, Kim S, Jeon M, Jung U-W, Lee J-H, Choi H-J, et al. Evaluation of the Apical Complex and the Coronal Pulp as a Stem Cell Source for Dentin-pulp Regeneration. J Endod. 2020; 46(2):224-231.e3. doi: 10.1016/j.joen.2019.10.025.

24. Dominici M, Le Blanc K, Mueller I, Slaper-Cortenbach I, Marini FC, Krause DS et al. Minimal criteria for defining multipotent mesenchymal stromal cells. The International Society for Cellular Therapy position statement. Cytotherapy. 2006; 8(4): 315-317. doi: $10.1080 / 14653240600855905$.

25. Nada OA, El Backly RM. Stem Cells From the Apical Papilla (SCAP) as a Tool for Endogenous Tissue Regeneration. Front Bioeng Biotechnol. 2018;6:103. doi:10.3389/ fbioe. 2018.00103

26. Basso FG, Pansani TN, Turrioni AP, Bagnato VS, Hebling J, de Souza Costa CA. In vitro wound healing improvement by low-level laser therapy application in cultured gingival fibroblasts. Int J Dent. 2012;2012:719452. doi: 10.1155/2012/719452.

27. Ginani F, Soares DM, Barreto MP, Barboza CA. Effect of lowlevel laser therapy on mesenchymal stem cell proliferation: a systematic review. Lasers Med Sci. 2015;30(8):2189-94. doi: 10.1007/s10103-015-1730-9.

28. Kheiri A, Amid R, Kheiri L, Namdari M, Mojahedi M, 
Kadkhodazadeh M. Effect of Low- Level Laser Therapy on Bone Regeneration of Critical-Size Bone Defects: A Systematic Review of In Vivo Studies and MetaAnalysis. Arch Oral Biol. 2020;117:104782. doi: 10.1016/j. archoralbio.2020.104782.

29. Huertas RM, Luna-Bertos ED, Ramos-Torrecillas J, Leyva FM, Ruiz C, García-Martínez O. Effect and clinical implications of the low-energy diode laser on bone cell proliferation. Biol Res Nurs. 2014;16(2):191-6. doi: 10.1177/1099800413482695.

30. Ballini A, Mastrangelo F, Gastaldi G, Tettamanti L, Bukvic $\mathrm{N}$, Cantore $\mathrm{S}$ et al. Osteogenic differentiation and gene expression of dental pulp stem cells under low-level laser irradiation: a good promise for tissue engineering. $J$ Biol Regul Homeost Agents. 2015; 29: 813-822.

31. Li W-T, Leu Y-C, Wu J-L. Red-Light Light-Emitting Diode Irradiation Increases the Proliferation and Osteogenic Differentiation of Rat Bone Marrow Mesenchymal Stem Cells. Photomed Laser Surg. 2010; 28(supl.1): S157-65. doi: 10.1089/pho.2009.2540.

32. Tabatabaei FS, Torshabi M, Nasab MM, Khosraviani K, Khojasteh A. Effect of low-level diode laser on proliferation and osteogenic differentiation of dental pulp stem cells. Laser Phys. 2015; 25(9): 095602. doi: 10.1088/1054-
660X/25/9/095602

33. Yang Y, Zhu T, Wu Y, Shu C, Chen Q, Yang J, et al. Irradiation with blue light-emitting diode enhances osteogenic differentiation of stem cells from the apical papilla. Lasers Med Sci. 2020; 35(9):1981-1988. doi: 10.1007/s10103-02002995-3.

34. Yuan Y, Yan G, Gong R, Zhang L, Liu T, Feng C, et al. Effects of Blue Light Emitting Diode Irradiation On the Proliferation, Apoptosis and Differentiation of Bone Marrow-Derived Mesenchymal Stem Cells. Cell Physiol Biochem. 2017;43(1):237-246. doi: 10.1159/000480344.

35. Szymanska J, Goralczyk K, Klawe JJ, Lukowicz M, Michalska M, Goralczyk B, et al. Phototherapy with lowlevel laser influences the proliferation of endothelial cells and vascular endothelial growth factor and transforming growth factor-beta secretion. J Physiol Pharmacol. 2013;64(3):387-91.

36. Colaco AS. An update on the effect of low-level laser therapy on growth factors involved in oral healing. J Dent Lasers. 2018; 12(2): 46-49. doi: 10.4103/jdl.jdl_1_18

37. Farivar S, Malekshahabi T, Shiari R. Biological Effects of Low Level Laser Therapy. J Lasers Med Sci. 2014; 5(2): 58-62. 